Revista Labor

Programa de Pós-graduação em Educação, Universidade Federal do Ceará

Fortaleza-CE-Brasil

\title{
Um resgate histórico do PROEJA do IF Sudeste MG: ecos trazidos pelos documentos
}

\section{A historical rescue of PROEJA from IF Sudeste MG: echoes brought by the documents}

\section{Un rescate histórico de PROEJA de IF Sudeste MG: ecos traídos por los documentos}

\author{
Costa, Nara Soares ${ }^{1}$ (Rio Pomba, MG, Brasil) \\ ORCID ID: https://orcid.org/0000.0002.8022.2978 \\ Brasileiro, Beatriz Gonçalves²(Muriaé, MG, Brasil) \\ ORCID ID: https://orcid.org/0000.0002.1543.2346 \\ Miranda, Paula Reis de ${ }^{3}$ (Rio Pomba, MG, Brasil) \\ ORCID ID: https://orcid.org/0000.0002.8066.7467
}

\begin{abstract}
Resumo
Este artigo tem como objetivo realizar um resgate histórico do Programa Nacional de Integração da Educação Profissional com a Educação Básica na Modalidade de Educação de Jovens e Adultos no Instituto Federal do Sudeste de Minas Gerais, campus Rio Pomba por meio da análise crítica dos ecos trazidos pelos documentos do curso técnico em Agente Comunitário de Saúde - PROEJA, integrado ao Ensino Médio, que vigorou nesse campus no período de 2008 a 2013. Para isso, a metodologia deste estudo foi de abordagem qualitativa, com caráter exploratório utilizando a pesquisa documental como instrumento de análise. Os resultados encontrados apontam que o perfil dos estudantes é formado principalmente por mulheres, com idade de até 30 anos, oriundos de Rio Pomba e de pequenas cidades ao seu entorno. O currículo do curso aponta tensões em relação à integração e ao atendimento às necessidades do público dessa modalidade. Quanto à gestão institucional, ainda ecoa a resistência de oferta de curso PROEJA na instituição, mesmo com as obrigações legais trazidas pelos documentos.
\end{abstract}

Palavras-chave: Educação de Jovens e Adultos. Técnico em Agente Comunitário de Saúde. Análise Documental. Perfil.

\begin{abstract}
This article aims to carry out a historical rescue of the National Program for the Integration of Professional Education with Basic Education in the Youth and Adult Education Modality at the Federal Institute of Southeast Minas Gerais, Rio Pomba campus through a critical analysis of the echoes brought by documents of the technical course in Community Health Agent - PROEJA, integrated to the High School, that was in force in this campus from 2008 to 2013 . For this, the methodology of this study was of qualitative approach, with exploratory character using the documentary research as instrument of analyze. The results found show that the profile of the students is formed mainly by women, aged up to 30 years old, from Rio Pomba and small towns around them. The course curriculum points out tensions in relation to integration and meeting the needs of the public in this modality. As for institutional management, the resistance of the PROEJA course offer at the institution still echoes, even with the legal obligations brought by the documents.

\footnotetext{
1 Servidora pública no Instituto Federal de Educação, Ciência e Tecnologia do Sudeste de Minas Gerais. nara.costa@ifsudestemg.edu.br

2 Professora do Instituto Federal do Sudeste de Minas Gerais. beatriz.brasileiro@ifsudestemg.edu.br

${ }^{3}$ Professora do IF Sudeste de Minas Gerais. Atua como professora do ProfEPT. paula.reis@ifsudestemg.edu.br
} 
Revista Labor

Programa de Pós-graduação em Educação, Universidade Federal do Ceará

Fortaleza-CE-Brasil

Keywords: Youth and Adult Education. Technician in Community Health Agent. Document Analysis. Profile.

\section{Resumen}

Este artículo tiene como objetivo realizar un rescate histórico del Programa Nacional para la Integración de la Educación Profesional con la Educación Básica en la Modalidad de Educación de Jóvenes y Adultos en el Instituto Federal del Sureste de Minas Gerais, campus Rio Pomba a través de un análisis crítico de los ecos aportados por documentos del curso técnico en Agente Comunitario de Salud PROEJA, integrado al Bachillerato, que estuvo vigente en este campus de 2008 a 2013. Para ello, la metodología de este estudio fue de abordaje cualitativo, con carácter exploratorio utilizando la investigación documental como instrumento de analizar. Los resultados encontrados muestran que el perfil de los estudiantes está formado principalmente por mujeres, de hasta 30 años, de Rio Pomba y de los pueblos de su entorno. El plan de estudios del curso señala tensiones en relación con la integración y la satisfacción de las necesidades del público en esta modalidad. En cuanto a la gestión institucional, la resistencia de la oferta de cursos de PROEJA en la institución aún resuena, incluso con las obligaciones legales que traen los documentos.

Palavras-Clave: Educación de jóvenes y adultos. Técnico en Agente de Salud Comunitaria, Análisis de Documentos. Perfil.

\section{Introdução}

A Rede Federal de Educação Profissional, Científica e Tecnológica (RFEPCT) configura-se, há mais de um século, como importante estrutura para efetivação do acesso à formação profissional. Entretanto, encontramos marcas da elitização de algumas instituições, já que "tornar-se aluno dessas escolas não é fácil, pois a concorrência para ingresso é muito elevada, uma vez que a quantidade de vagas que podem oferecer é muito menor do que a demanda" (MOURA, 2007, p. 21). Uma comprovação disto é a tardia inclusão da Educação de Jovens e Adultos (EJA) na RFEPCT. Essa modalidade de ensino, destinada às pessoas que não tiveram acesso ou não concluíram seus estudos de nível fundamental e médio em idade regular, só passou a fazer parte da RFEPCT, de forma institucionalizada, a partir de $2004^{4}$.

Essa inserção ocorreu por meio do Programa Nacional de Integração da Educação Profissional com a Educação Básica na modalidade de Educação de

\footnotetext{
${ }^{4}$ Vale destacar que o primeiro decreto que institucionaliza o PROEJA é datado de 2005, entretanto, anteriormente a ele, algumas instituições já experenciavam atividades de cursos na Educação de Jovens e Adultos dentro da ETP, como por exemplo, os Cefet's de Minas Gerais, Pelotas, Santa Catarina, Espírito Santo, entre outros, sem haver integração à Educação Profissional.
} 


\section{Revista Labor}

Programa de Pós-graduação em Educação, Universidade Federal do Ceará

Fortaleza-CE-Brasil

Jovens e Adultos (PROEJA). O PROEJA foi um programa, que visava oferecer oportunidades educacionais aos jovens e adultos que não finalizaram o ensino fundamental e àqueles que não concluíram o ensino médio, qualificando-os profissionalmente, promovendo a elevação da escolaridade e a inclusão desses sujeitos no mundo do trabalho. Segundo o Decreto $n^{\circ}$ 5.840/06 (BRASIL, 2006), as instituições federais de educação profissional deveriam implantar o PROEJA até o ano de 2007, oferecendo, no mínimo, $10 \%$ (dez por cento) de suas vagas, do ano anterior, para o público jovem e adulto trabalhador e, ampliar essa oferta a partir de 2007:

Art $2^{\circ}$ As instituições federais de educação profissional deverão implantar cursos e programas regulares do PROEJA até o ano de 2007.

$\S 1^{\circ}$ As instituições referidas no caput disponibilizarão ao PROEJA, em 2006, no mínimo dez por cento do total das vagas de ingresso da instituição, tomando como referência o quantitativo de matrículas do ano anterior, ampliando essa oferta a partir do ano de 2007 (BRASIL, 2006, s/p.).

Apesar de grande parte da RFEPCT não ter conseguido cumprir a determinação desse artigo, a Lei $n^{\circ}$ 11.892/08 (BRASIL, 2008), que criou os Institutos Federais (IFs) reforçou, em seu artigo $7^{\circ}$, inciso I e $8^{\circ}$, a importância dessa modalidade dentro das finalidades dos IFs:

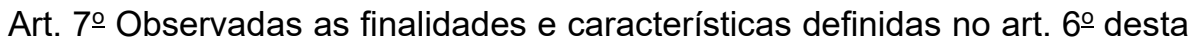
Lei, são objetivos dos Institutos Federais:

I - ministrar educação profissional técnica de nível médio, prioritariamente na forma de cursos integrados, para os concluintes do ensino fundamental e para o público da educação de jovens e adultos;

Art. 8o No desenvolvimento da sua ação acadêmica, o Instituto Federal, em cada exercício, deverá garantir o mínimo de 50\% (cinquenta por cento) de suas vagas para atender aos objetivos definidos no inciso I do caput do art. 7을 desta Lei, [...] (BRASIL, 2008, s/p, grifo nosso).

Apesar de ainda presente na rede, escrevemos esse artigo num momento em que o PROEJA e a educação não são prioridades para os governantes do país em que vivemos. O governo atual, em 2019, pelo Decreto nº 9.465 (BRASIL, 2019), dissolveu a estrutura que se dedicava à modalidade Educação de Jovens e Adultos (EJA): Secretaria de Educação Continuada, Alfabetização, Diversidade e Inclusão 
Programa de Pós-graduação em Educação, Universidade Federal do Ceará

Fortaleza-CE-Brasil

(SECADI) e hoje, não há, no Ministério da Educação, uma secretaria responsável por essa modalidade de ensino.

É nesse contexto incerto que procuramos refletir sobre a importância da história do PROEJA no Instituto Federal de Educação, Ciência e Tecnologia do Sudeste de Minas Gerais, campus Rio Pomba, por meio do Curso Técnico em Agente Comunitário de Saúde integrado do Ensino Médio que vigorou nesse campus, no período de 2008 a 2013, a fim de encontrar rastros e sentidos da educação formativa e emancipatória.

Preservar a história de um curso não significa arquivar simplesmente documentos sobre ele, apesar da grande importância de resgate e preservação do passado; significa, também, por meio de seus documentos, criar estratégias para conhecer as particularidades de cada momento vivido e oportunidades para utilizá-los nas decisões do presente, bem como para planejar o futuro.

Diante desse entendimento, este artigo tem seu olhar voltado para o resgate histórico do curso Técnico em Agente Comunitário de Saúde integrado ao Ensino Médio do IF Sudeste MG - campus Rio Pomba apoiado na legislação e na análise documental. Esse curso fora implantado nessa instituição no ano de 2008, ano marcado pela criação dos IFs e pela primeira ampliação da rede (FRIGOTTO, 2018).

Isso porque, a Educação de Jovens e Adultos (EJA) está incluída na rede pública de ensino há décadas, sendo oferecida nos níveis fundamental e médio prioritariamente por prefeituras e pelos estados brasileiros. Entretanto, foi a partir dos anos 2000 que a EJA tem maiores incentivos e passa a ser ofertada de forma mais ampla, na RFEPCT por meio da Portaria 2.080/2005 (BRASIL, 2005) e dos decretos 5.478/2005 (BRASIL, 2005) e 5.840/06 (BRASIL, 2006).

O Curso Técnico em Agente Comunitário de Saúde integrado do Ensino Médio perdurou no campus Rio Pomba por (04) quatro anos, sendo ofertada 4 turmas (2008 - 2013). Contudo, a partir de 2014, a oferta do PROEJA foi suspensa sob a justificativa de baixa procura do curso pela comunidade. Essa baixa procura pode estar relacionada ao fato das prefeituras da região não exigirem curso de nível técnico para a atuação dos profissionais de Agente Comunitário de Saúde (MIRANDA, 2015). Desde então, o campus Rio Pomba não ofertou nenhum curso voltado para a 
Revista Labor

Programa de Pós-graduação em Educação, Universidade Federal do Ceará

Fortaleza-CE-Brasil

educação de jovens e adultos articulado à EPCT e, consequentemente, descumpre o exigido pela legislação pertinente.

\section{0 percurso metodológico}

A pesquisa foi marcada por uma abordagem qualitativa, com caráter exploratório, no formato de estudo de caso, uma vez que objetiva "descrever a situação do contexto em que está sendo feita determinada investigação" (GIL, 2008, p. 54), sendo complementado com a análise documental do curso Técnico em ACS PROEJA, no IF Sudeste MG, campus Rio Pomba no período delimitado entre 2008 e 2013.

Com o objetivo de analisar os dados a fim de compreender os impactos que - PROEJA trouxe para o IF Sudeste MG, campus Rio Pomba realizamos a pesquisa documental em registros institucionais a fim de dar embasamento aos fatos investigados e enriquecer o estudo.

Cabe destacar que a pesquisa documental é muito semelhante à pesquisa bibliográfica, porém,

enquanto a pesquisa bibliográfica se utiliza fundamentalmente das contribuições dos diversos autores sobre determinado assunto, a pesquisa documental vale-se de materiais que não recebem ainda um tratamento analítico, ou que ainda podem ser reelaborados de acordo com os objetos da pesquisa (GIL, 2008, p. 51).

Nesse sentido, a análise documental possibilita o conhecimento passado, a investigação dos processos de mudança social e cultural, a obtenção de dados com menor custo, sem que haja o constrangimento dos sujeitos investigados (GIL, 2010). Além disso, possibilita uma maior familiaridade entre o pesquisador e o seu objeto de estudo.

Feitas essas considerações, cabe mencionar que para a realização da coleta de dados, foram realizadas, entre maio e junho de 2020 , consultas aos documentos referentes ao curso técnico em ACS - PROEJA; acessos à página eletrônica do IF Sudeste de Minas Gerais, campus Rio Pomba para consulta de portarias e resoluções emitidas e levantamentos dos documentos armazenados e 
Revista Labor

Programa de Pós-graduação em Educação, Universidade Federal do Ceará

Fortaleza-CE-Brasil

disponibilizados pela Coordenação Geral de Ensino Técnico e Secretaria dos Cursos Técnicos.

Após a seleção do material, foi realizada a leitura e a triagem dos mesmos, organização dos dados coletados e, por meio da análise documental buscou-se relacionar as informações encontradas e descrever criticamente a história do curso técnico em ACS - PROEJA no campus Rio Pomba.

\section{Ecos trazidos pelos documentos}

\subsection{Os sujeitos e os acessos}

Primeiramente, é preciso ressaltar que a EJA/EPCT teve suas primeiras ações, no campus Rio Pomba, em 2006, em razão do Decreto n 5.840/06 (BRASIL, 2006). Nessa época, a instituição nomeada de Centro Federal de Educação Tecnológica de Rio Pomba - CEFET-RP firmou uma parceria com a Prefeitura da cidade de Lima Duarte para a oferta do curso técnico em Informática na modalidade EJA, na forma de concomitância. Esse projeto pioneiro contribuiu, posteriormente, para a implantação do PROEJA no campus Rio Pomba. Todavia, durante o transcorrer do curso, verificou-se pouco interesse da população daquela cidade e altos índices de desistência e, logo após a conclusão da primeira turma de técnicos desse curso, o convênio foi dissolvido por "dificuldades operacionais" (BARBOSA, 2010, p.51).

Em 2008, o ainda CEFET-RP organizou-se para ofertar a primeira turma do PROEJA e, em agosto deste mesmo ano, seu Conselho Diretor, aprovou a implantação dessa modalidade de ensino, por meio do curso Técnico em Agente Comunitário de Saúde (ACS) integrado ao Ensino Médio sob a alegação de ser "uma área carente de qualificação" (BARBOSA, 2010, p. 52).

Tal ação demonstra que a implantação do PROEJA, no CEFET-RP, ocorreu para cumprir uma determinação legal e atender um projeto de política educacional de inclusão permanente da rede federal. Isso porque, nos documentos analisados, para o início da oferta do PROEJA, não há indícios de que houve discussão na comunidade acadêmica, adaptação dos espaços acadêmicos e tampouco formação do corpo técnico administrativo e dos professores para atuarem nesta modalidade de ensino que exige um modo próprio de ser e de aprender. 


\section{Revista Labor}

Programa de Pós-graduação em Educação, Universidade Federal do Ceará

Fortaleza-CE-Brasil

Segundo o Parecer $n^{\circ}$ CNE/CEB 11/2000:

O termo modalidade é diminutivo latino de modus (modo, maneira) e expressa uma medida dentro de uma forma própria de ser. Ela tem, assim, um perfil próprio, uma feição especial diante de um processo considerado como medida de referência. Trata-se, pois, de um modo de existir com característica própria. (BRASIL, 2000, p.25).

É preciso mencionar, ainda, que a inclusão do PROEJA nas instituições ocorreu devido a "dívidas históricas do Estado brasileiro com a sociedade" (BRASIL, 2007, p. 32). Além disso, a implantação do PROEJA na rede federal, por meio de decreto, significou uma ação emergencial e imprescindível devido à baixa expectativa de inclusão de jovens e adultos de classes populares no sistema público de educação profissional e ampara-se nas experiências apartadas de algumas instituições de Educação Profissional e Tecnológica nessa modalidade (BRASIL, 2007).

Nesse contexto, a primeira turma do curso técnico em ACS - PROEJA iniciou no período noturno, com a abertura de 35 vagas por meio do Edital $n^{\circ} 007 / 2008$, com os seguintes critérios de seleção: idade (os candidatos mais velhos teriam precedência), lapso de tempo desde a conclusão do Ensino Fundamental (teriam preferência os candidatos que concluíram o Ensino Fundamental há mais tempo) e experiência comprovada na área de Saúde. Nessa primeira seleção, houve 105 candidatos e 29 realizaram a matrícula no curso (MIRANDA, 2015).

Encontramos, nos estudos de Miranda (2015), dados quantitativos (Tabela 1) sobre a seleção e a conclusão no curso ACS-PROEJA.

Tabela 01 - Detalhamento da seleção e conclusão do ACS - PROEJA

\begin{tabular}{|c|c|c|c|c|c|c|}
\hline Turma & $\begin{array}{l}\text { Período } \\
\text { do }\end{array}$ & Vagas & Candidatos & $\begin{array}{c}\text { Relação } \\
\text { candidatos/vaga }\end{array}$ & Ingressantes & Concluintes \\
\hline & Curso & & & & & \\
\hline $1^{a}$ & $\begin{array}{c}2008 / I I ~ a ~ \\
2010 / I I\end{array}$ & 35 & 105 & 3 & 29 & 22 \\
\hline $2^{a}$ & $\begin{array}{c}2009 / I I a \\
2011 / I I\end{array}$ & 40 & 43 & 1,075 & $42^{*}$ & 16 \\
\hline
\end{tabular}


$3^{\mathrm{a}} \quad 2011 / \mathrm{l}$ a $\quad 40$

2012/II $4^{\mathrm{a}} \quad 2012 / \mathrm{la} \quad 40$

2013/II

* 40 ingressantes pelo processo seletivo e 2 alunos provenientes de trancamento de matrícula.

Fonte: (MIRANDA, 2015)

Nos três primeiros processos de seleção para o curso (2008, 2009 e 2011), o número de candidatos foi maior que o número de vagas, sendo que, apenas, na turma de 2009-2011, houve o preenchimento total do número de vagas na matrícula.

Miranda (2015) ressalta que a baixa procura desse curso, em 2012, pode ter sido em decorrência do fato de que as prefeituras da região realizaram concurso público para ACS, mas não exigiram curso de nível técnico para a atuação desses profissionais. Contudo, a conciliação entre trabalho, família e escola, também, pode ter sido um fator que contribuiu para essa baixa procura pelo curso.

Segundo nossas análises, das 128 pessoas jovens e adultas que se matricularam no curso no período de 2008 a 2013, houve a predominância de mulheres (74\%), conforme verificamos na Tabela 02. Essa predominância pode ter ocorrido pelo maior número de mulheres que atuavam como agentes comunitários de saúde e, consequentemente, terem buscado a qualificação profissional. Além disso, esse desequilíbrio quanto ao gênero condiz com a afirmativa do Documento Base (2007) que afirma que a maioria dos sujeitos da educação de jovens e adultos pertence a uma classe especial: jovens, mulheres, negros, pobres, idosos e outros.

Quanto à situação de permanência e conclusão dos estudantes durante o curso, as turmas de 2009 e 2011 tiveram os maiores índices de evasão; todavia, na turma de 2012, onde ingressaram apenas 20 alunos, esse índice foi reduzido.

A primeira turma do curso (2008) teve um alto índice de conclusão do curso, o que não ocorreu na segunda (2009) e terceira turma (2011). Já, na quarta turma do curso (2012), com apenas 20 ingressantes, 95\% dos alunos concluíram o curso e 5\% foi reprovado. 


\section{Revista Labor}

Programa de Pós-graduação em Educação, Universidade Federal do Ceará

Fortaleza-CE-Brasil

Quanto à idade dos alunos, percebemos a existência de poucos alunos com menos de 20 anos (3\%) e com mais de 60 anos (2\%). Entretanto, verificamos que a maioria dos alunos, que compôs as turmas desse curso, era jovem, com idade inferior e/ou igual à 30 anos (48\%), apesar de ter tido estudantes adultos com mais de $30(24 \%)$ e $40(20 \%)$ anos. Tal fato confirma o que já suspeitávamos: a juvenilização da EJA nos cursos do PROEJA. No trabalho de Silva e Almeida (2011), também verificaram que mais de $72 \%$ dos alunos do PROEJA do Paraná possuíam idade de até 30 anos, uma proporção similar ao encontrado no curso técnico em ACS-PROEJA.

Já, quanto à origem, verificamos que os alunos não eram oriundos apenas da cidade de Rio Pomba (52\%), sendo que alguns residiam em municípios vizinhos situados a menos de $45 \mathrm{~km}$ da cidade de Rio Pomba. Esse pequeno distanciamento facilitava o deslocamento das pessoas que trabalhavam e estudavam, entretanto, para o deslocamento dessas pessoas para o campus Rio Pomba, todas as noites, havia a necessidade de transportes, muitos deles, particulares.

Tabela 2- Perfil dos alunos das turmas do curso técnico em ACS-PROEJA no período de 2008-2013

\begin{tabular}{lll}
\hline Sexo & $\mathbf{N}^{\circ}$ & $\%$ \\
\hline Masculino & 34 & $26 \%$ \\
Feminino & 94 & $74 \%$ \\
\hline Idade & & \\
$18-20$ & 04 & $3 \%$ \\
$21-30$ & 58 & $45 \%$ \\
$31-40$ & 31 & $24 \%$ \\
$41-50$ & 26 & $20 \%$ \\
$51-60$ & 07 & $6 \%$ \\
$61-70$ & 02 & $2 \%$ \\
\hline Reside em & & \\
\hline Rio Pomba & 67 & $52 \%$
\end{tabular}


Revista Labor

Programa de Pós-graduação em Educação, Universidade Federal do Ceará

Fortaleza-CE-Brasil

Fora do Município $61 \quad 48 \%$ de Rio Pomba

Fonte: Elaborado pelas autoras com base nos dados fornecidos pela secretaria dos cursos técnicos do campus Rio Pomba

Já, quanto ao perfil dos professores que atuaram no curso técnico em ACS, constatamos que $61 \%$ eram do sexo feminino. Dos 60 professores que atuaram no curso, havia a predominância de professores concursados e efetivos ${ }^{5}$ no IF Sudeste MG (54\%), sendo que dessa categoria, 69\% possuíam formação acadêmica em licenciatura e 31\% tinham formação acadêmica em bacharelado. Também atuaram no curso, professores substitutos ${ }^{6}(46 \%)$, sendo que desses $61 \%$ eram licenciados e $39 \%$ eram bacharéis. (Gráfico 1 )

Gráfico 1- Perfil dos professores que atuaram no curso técnico em ACS-PROEJA no período de $2008-2013$

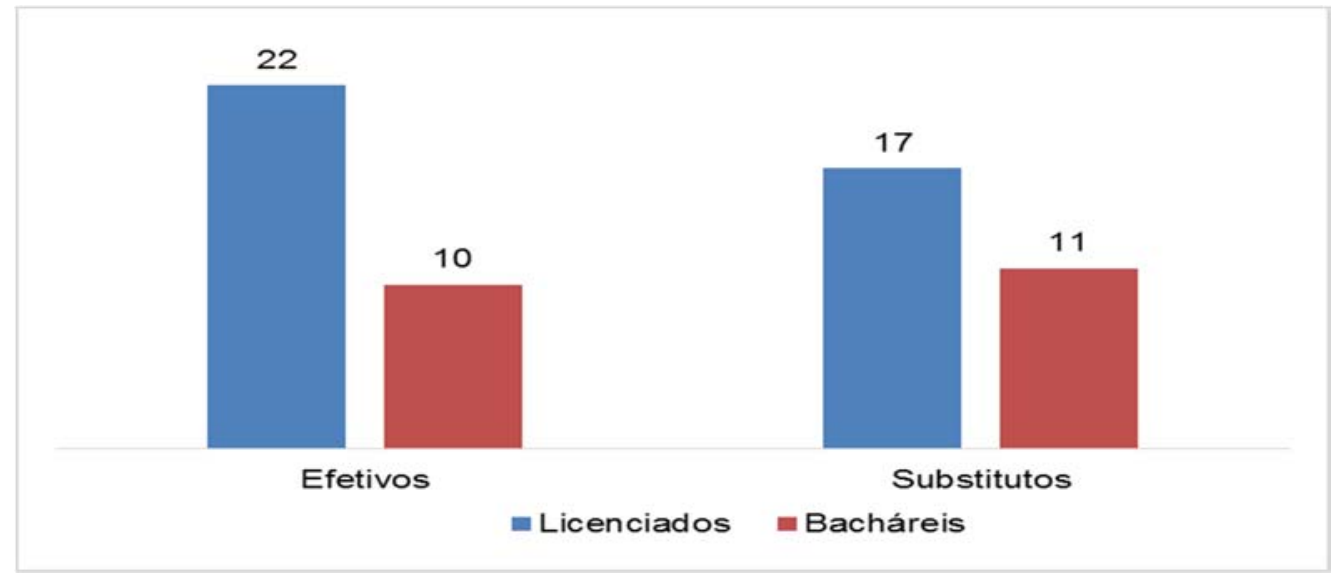

Fonte: Acervo das pesquisadoras

Os professores, com formação acadêmica em bacharelado, os bacharéis, na sua maioria (91\%), ministraram as disciplinas profissionalizantes sem terem recebido formação que os tornassem professores, apenas (9\%) lecionaram disciplinas da educação básica. Entretanto, conforme afirma Moura (2017, p. 18), é preciso esclarecer que esses profissionais "atuam como tal em disciplinas próprias do campo

5 Professores efetivos são aqueles que ingressam na instituição por meio de concurso público.

6 Professores substitutos são aqueles que trabalham na instituição por meio de contratos de trabalhos por um período de, no máximo, dois anos. 
Programa de Pós-graduação em Educação, Universidade Federal do Ceará

Fortaleza-CE-Brasil

do seu bacharelado em uma turma do PROEJA, sem conhecer o que é ser professor de uma forma geral e, muito menos, professor da EJA".

Já, os professores com formação acadêmica em licenciatura eram aqueles que ministraram disciplinas de formação geral, contudo, é preciso ressaltar que, segundo Moura (2017), nos cursos de licenciaturas, geralmente, não há, em seus currículos, conteúdos sobre a educação profissional e tão pouco sobre a educação de jovens e adultos. Assim, "o professor chega na sala de aula do PROEJA sem conhecer os seus sujeitos" (MOURA, 2017, p. 18).

Júnior (2016), afirma, também, que, a EJA, ainda, "não é tratada como deveria nos cursos Licenciatura, através dos formadores de professores, de modo a formar professores comprometidos com a natureza que a modalidade apresenta". (JÚNIOR, 2016, p. 72) e, isso dificulta a oferta de cursos dessa modalidade de ensino, uma vez que ela possui alunos com perfil bem heterogêneo.

Nessa perspectiva, percebemos que os professores atuantes no curso técnico em ACS-PROEJA, independente de serem licenciados ou bacharéis, podem não ter tido formação acadêmica para atuar com o público jovem e adulto trabalhador.

A ausência de professores capacitados para atuarem com a educação de jovens e adultos pode ter dificultado a oferta desse curso no campus Rio Pomba, já que esse público é peculiar na área do conhecimento e, conforme prescreve o Documento Base (2007), exige

\begin{abstract}
a correspondente formação de professores para atuar nessa esfera. Isso não significa que um professor que atue na educação na educação básica ou profissional não possa trabalhar com a modalidade EJA. Todos os professores podem e devem, mas, para isso, precisam mergulhar no universo de questões que compõem a realidade desse público, investigando seus modos de aprender de forma geral, para que possam compreender e favorecer essas lógicas de aprendizagem no ambiente escolar. (BRASIL, 2007, p. 36).
\end{abstract}

Assim, ao analisarmos as categorias dos professores, acreditamos que a presença de professores substitutos (46\%), com alta rotatividade e pouco tempo de permanência na instituição, e a ausência de formação dos professores para a EJA/EPCT demonstra uma fragilidade na oferta do curso técnico em ACS-PROEJA no campus Rio Pomba. Isso porque a aproximação dos professores com os princípios 
Revista Labor

Programa de Pós-graduação em Educação, Universidade Federal do Ceará

Fortaleza-CE-Brasil

e legislação da EJA e do PROEJA poderia auxiliar no desenvolvimento desse programa nesse campus, como em muitos outros.

\subsection{0 currículo}

Quanto à estrutura curricular do curso, verificamos que a primeira turma do curso técnico em ACS - PROEJA teve duração de dois anos (4 semestres) e prazo máximo para conclusão em três anos (6 semestres). De segunda a sexta-feira os alunos tinham cinco aulas de 45 minutos cada, com início às 18:30h e término às 22:25h e nos sábados eram previstas atividades a serem cumpridas à distância, totalizando mais $1 \mathrm{~h} 30$ min semanais com uma carga horária total de 2440 horas, distribuídas em doze disciplinas da Base Nacional Comum e vinte e três disciplinas de conteúdos da formação profissional.

A partir da segunda turma, iniciada em agosto de 2009, o curso técnico em ACS-PROEJA teve alteração em sua estrutura curricular, passando a contabilizar carga horária total de 2520 horas, distribuídas em doze disciplinas da Base Nacional Comum, vinte e duas disciplinas de conteúdos da formação profissional e uma disciplina da parte diversificada, mais 100 horas de estágio.

Em 2012, houve uma reformulação do PPP do curso, na qual foram reorganizadas as cargas horárias das disciplinas, mantendo a carga horária total do curso em 2.520 horas e a demais estruturas do curso determinadas desde a primeira turma em 2008 e, alterou o quantitativo de disciplinas de conteúdos de formação profissional para dezenove disciplinas, eliminando as disciplinas de: Processo de Trabalho em Saúde, Saúde Ambiental e Política Nacional de Saúde.

Constatamos, assim, que tanto a matriz curricular do curso ACS - PROEJA elaborada em 2008, quanto às de 2009 e 2012, estavam em consonância com o Catálogo Nacional de Cursos Técnicos (BRASIL, 2017), que prevê a carga horária de 1200 horas para a formação profissional específica (integralização das unidades curriculares) e com o artigo $4^{\circ}$ do Documento Base (BRASIL, 2007), que determina que

Art. $4^{\circ}$ Os cursos de educação profissional técnica de nível médio do PROEJA deverão contar com carga horária mínima de duas mil e quatrocentas horas, assegurando-se cumulativamente: I - a destinação de, no mínimo, mil e duzentas horas para a formação geral; II - a carga horária mínima 
estabelecida para a respectiva habilitação profissional técnica; e III - a observância às diretrizes curriculares nacionais e demais atos normativos do Conselho Nacional de Educação para a educação profissional técnica de nível médio, para o ensino fundamental, para o ensino médio e para a educação de jovens e adultos (BRASIL, 2007, p.69).

No entanto, apesar dessa estrutura curricular estar em conformidade com a legislação vigente, percebemos que para um curso voltado para o público jovem e adulto trabalhador com conclusão em dois anos, havia um número excessivo de disciplinas e uma carga horária exorbitante. Isso porque o curso era dividido por quatro semestres, sendo que cada semestre era composto, em média, por dezesseis disciplinas e com a carga horária sempre acima do exigido em lei.

Cabe relembrar que o currículo integrado foi instituído antes da implantação dos cursos PROEJA, por meio do Decreto $n^{\circ}$ 5.154/04 (BRASIL, 2004), em substituição ao Decreto $n^{\circ} 2.208 / 97$ (BRASIL, 1997) e possibilitou a oferta de ensino médio integrado ao ensino técnico com matrícula única em todo o país e, permitiu, também, a oferta dos cursos técnicos concomitantes ${ }^{7}$ e subsequentes ${ }^{8}$.

Nessa perspectiva, verificamos que todas as matrizes curriculares foram confeccionadas em um modelo padrão de currículo técnico articulado ao ensino médio, realizando, apenas, a junção das disciplinas do ensino médio (formação básica) com as do ensino técnico (formação profissional), sem deixar claro, portanto, a realização da integração entre as disciplinas e a educação voltada o público de jovem e adulto trabalhador.

É nítida a sobreposição dos conteúdos curriculares nas matrizes do curso técnico em ACS-PROEJA. Percebemos que em cada componente curricular havia conteúdos relacionados a determinados assuntos sem haver comunicação e integração entre eles, não distinguindo, assim, a característica de currículo integrado, vez que cada componente curricular não fazia parte de um todo, ou seja, não havia, por exemplo, a interdisciplinaridade entre as disciplinas de Saúde da Mulher, Saúde

7 Os cursos técnicos concomitantes são aqueles em que o aluno possui duas matrículas diferentes: uma no curso técnico e outra no ensino médio e ao final do curso recebe duas certificações distinta e, pode cursar o ensino técnico e o ensino médio na mesma instituição ou em instituições diferentes.

80 s cursos técnicos subsequentes são aqueles em que o aluno cursa o ensino técnico, após a conclusão do ensino médio. 
do Homem, Saúde do Idoso e de Biologia, que tratavam, muitas vezes, de assuntos relacionados e/ou complementares.

O elevado número de disciplinas, desse curso, não garantia a formação integrada entre os conhecimentos adquiridos na escola e no dia-a-dia profissional e, tampouco, o desenvolvimento das competências previstas no projeto político pedagógico na formação do técnico em ACS como um sujeito ativo e crítico no mundo do trabalho.

Competências no âmbito da mobilização social, integração entre a população e as equipes de saúde e do planejamento das ações:

- Desenvolver ações que busquem a integração entre as equipes de saúde e a população adstrita à Unidade de Saúde, considerando as características e as finalidades do trabalho de acompanhamento de indivíduos e grupos sociais ou coletividades.

- Realizar, em conjunto com a equipe, atividades de planejamento e avaliação das ações de saúde no âmbito de adstrição da Unidade de Saúde. - Desenvolver ações de promoção social e de proteção e desenvolvimento da cidadania no âmbito social e da saúde. (IF SUDESTE MG, 2012, p. 12).

O Documento Base (BRASIL, 2007) indica, ainda, que para a elaboração e o desenvolvimento de uma proposta de integração da educação básica com a educação profissional na modalidade de educação de sujeitos jovens e adultos trabalhador, é preciso criar propostas pedagógicas específicas para esse público:

Um programa, pois, de educação de jovens e adultos nesse nível de ensino necessita, tanto quanto nos demais níveis, e para outros sujeitos, formular uma proposta político-pedagógica específica, clara e bem definida para que possa atender as reais necessidades de todos os envolvidos, e oferecer respostas condizentes com a natureza da educação que buscam, dialogando com as concepções formadas sobre o campo de atuação profissional, sobre o mundo do trabalho, sobre a vida (BRASIL, 2007, p. 36).

Assim, nos três projetos do curso técnico em ACS-PROEJA analisados, percebemos a singular intenção de oferecer uma educação integrada e o objetivo de promover, na formação do estudante, a elevação da escolaridade e a melhor preparação para o exercício profissional, desenvolvendo um perfil melhor ajustado à função. Contudo, sua estrutura organizacional curricular não garantia um ensino articulado entre teoria e prática, de forma a permitir a formação profissional pela 
Revista Labor

Programa de Pós-graduação em Educação, Universidade Federal do Ceará

Fortaleza-CE-Brasil

construção de conhecimentos que possibilitam ao estudante atuar no mundo do trabalho.

Sobre essa estrutura, Ciavatta (2005) entende que a formação integrada significa superação do ser humano segmentado historicamente pela divisão social do trabalho e, traz como princípio de integração:

\begin{abstract}
O que é integrar? É tornar íntegro, inteiro, o que? A palavra toma o sentido moral em alguns usos correntes. Mas não é disto que trata aqui. Remetemos o termo ao seu sentido de completude, de compreensão das partes no seu todo ou da unidade no diverso, de tratar a educação como uma totalidade social, isto é, nas múltiplas mediações históricas que concretizam os processos educativos. No caso da formação integrada ou do ensino médio integrado ao ensino técnico, queremos que a educação profissional em todos os seus campos onde se dá a preparação para o trabalho: seja nos processos produtivos, seja nos processos educativos como a formação inicial, como o ensino técnico, tecnológico ou superior. Significa que buscamos enfocar o trabalho como princípio educativo, no sentido de superar a dicotomia trabalho manual/ trabalho intelectual, de incorporar a dimensão intelectual ao trabalho produtivo, de formar trabalhadores capazes de atuar como dirigentes e cidadãos (CIAVATTA, 2005, p.84).
\end{abstract}

Afinal, realizar o ensino técnico integrado não significa "somar currículos e/ou as cargas horárias referentes ao ensino médio e às habilitações profissionais" (RAMOS, 2010, p. 52). Significa, todavia, associar ao currículo, conhecimentos gerais e específicos, cultura e trabalho, tecnologia e humanismo, uma vez que esse ensino busca formar trabalhadores para serem cidadãos, sujeitos de sua história.

\title{
2.3 A Gestão Institucional
}

Já, com o objetivo de compreender o que a política de gestão do IF Sudeste MG determina em relação à oferta do PROEJA, analisamos o Plano de Desenvolvimento Institucional (PDI) proposto para o período de 2014/2-2020 (IF SUDESTE MG, 2014) $)^{9}$ e, constatamos, que, de maneira geral, ofertar o PROEJA no IF Sudeste de MG não tem sido uma prioridade da comunidade acadêmica.

\footnotetext{
9 O PDI é um documento construído coletivamente entre os servidores do IF Sudeste MG com o objetivo de ser uma ferramenta de planejamento e gestão da instituição. As orientações nele presentes são previstas para vigorarem por um determinado período, geralmente, por cinco anos, para que as decisões desse período sejam tomadas de acordo com as oportunidades, potencialidades e limitações institucionais verificadas coletivamente (IF SUDESTE MG, 2014).
} 


\section{Revista Labor}

Programa de Pós-graduação em Educação, Universidade Federal do Ceará

Fortaleza-CE-Brasil

No período de 2014/2 a 2020/1, não houve ampliação da oferta dos cursos na modalidade PROEJA, não havendo, portanto, criação de nenhum novo curso dessa modalidade de ensino. Um exemplo disso é o número de matrículas voltadas para o PROEJA no referido período (Gráfico 2).

Gráfico 2 - Quantitativo de Matrículas anuais no Instituto Federal do Sudeste de MG,

conforme os diferentes níveis de ensino, no período de 2014 a 2019.

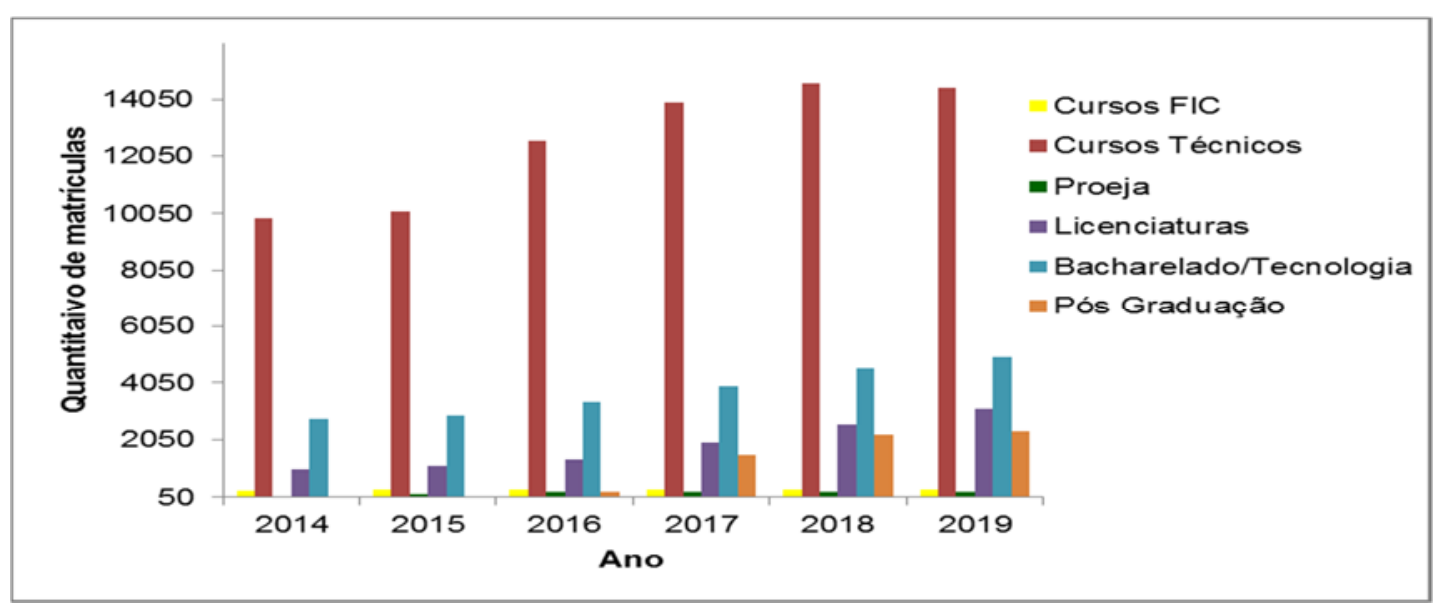

Fonte: Elaborado pelas autoras com base nos dados do IF SUDESTE MG, 2014, p. 333

Assim, apesar de registrado, no PDI, que a implementação do PROEJA já teria sido superada em 2014 no IF Sudeste MG (IF SUDESTE MG, 2014), constatamos que, nesse ano, foram destinadas 2,13\% das vagas para a EJA e, em 2019, no planejamento das vagas para os cursos que seriam ofertados, essa porcentagem foi reduzida para $1,45 \%$.

Isto posto, percebemos que metas são traçadas, mas a legislação ainda está longe de ser atendida quando se trata da oferta da EJA na EPCT. Um exemplo disso é o IF Sudeste MG não alcançar os $10 \%$ de vagas voltadas para a educação do jovem e adulto trabalhador, conforme determina o decreto $n^{\circ}$ 5.840/06 (BRASIL, 2006), e ainda, diminuir a possibilidade de oferta de cursos para essa modalidade de ensino em seu PDI.

\section{Considerações Finais}

Para concluir, destacamos que o curso técnico em ACS - PROEJA perdurou no IF Sudeste MG, campus Rio Pomba por quatro anos, sendo ofertadas 
Programa de Pós-graduação em Educação, Universidade Federal do Ceará

Fortaleza-CE-Brasil

quatro turmas. Ao realizarmos esse resgate histórico, constatamos que a oferta do PROEJA, nessa instituição, ocorreu para cumprir uma determinação prevista na legislação vigente.

Com esse estudo, foi possível, também, por meio dos documentos preservados pela instituição, conhecer e descrever o perfil dos atores que participaram da história do curso técnico em ACS-PROEJA. A maioria dos alunos era composta por mulheres, com idade até 30 anos e oriundas da cidade de Rio Pomba e região e, nas turmas de 2009 e 2011 houve um maior número de alunos evadidos. A equipe de professores era formada, em sua maioria, por mulheres e por professores efetivados e concursados no IF Sudeste MG e, apesar de serem professores licenciados, podem não ter tido formação acadêmica para atuar com o público jovem e adulto trabalhador, o que pode ter comprometido o desenvolvimento desse programa nesse campus, como em muitos outros.

Quanto à estrutura curricular do curso ACS-PROEJA, percebemos que, apesar dele ter sido elaborado e desenvolvido como integrado, houve uma justaposição de disciplinas, ocasionando, a oferta de um quantitativo excessivo de disciplinas para uma educação voltada para as pessoas jovens e adultas trabalhadoras com conclusão em dois anos, demonstrando, assim, uma fragilidade na oferta desse curso.

É preciso ressaltar que, os alunos do PROEJA, ao ingressarem no ambiente escolar, se deparam diante de diferentes realidades: diferenças culturais, demandas e possibilidades de melhoras no trabalho e dos conhecimentos já adquiridos. Esses fatores podem incentivar ou desestimular a permanência deles no curso. Portanto, a estrutura curricular desse curso precisava ter sido desenvolvida como um ensino integrado ao mundo do trabalho, a fim de estimular a aprendizagem, o trabalho colaborativo, a criatividade e as necessidades e tensões existentes na sociedade em que vivem.

Lado outro, registramos que apesar dessa modalidade de ensino ter sido incorporada legalmente no âmbito do IF Sudeste MG como política pública, a oferta está muito aquém do exigido pela legislação, já que essa instituição não cumpre a legislação vigente. 
Programa de Pós-graduação em Educação, Universidade Federal do Ceará

Fortaleza-CE-Brasil

Assim, a partir da análise dos dados e da verificação de não cumprimento da missão de ofertar educação profissional para jovens e adultos trabalhadores, percebemos que é de fundamental importância resgatar a história do curso dessa modalidade a fim de sensibilizar, compreender e institucionalizar a missão dos profissionais da RFEPCT para com esse público e toda a sociedade. Esse tipo de resgate vai além de registrar as experiências vividas, pois também procura averiguar os desafios e as potencialidades revelados com esse curso e os impactos causados neste campus, vez que a inclusão do público jovem e adulto trabalhador, no ambiente escolar, foi inovadora.

Nessa perspectiva, acreditamos que é imprescindível o resgate histórico do PROEJA IF Sudeste de Minas Gerais, no campus Rio Pomba para que ele não caia no esquecimento e não se dissolva no tempo. Essa importância marca legado dessa modalidade de ensino para a sociedade, e pode contribuir para a questão do pertencimento ao colaborar com o fortalecimento da imagem, identidade e reputação dessa instituição, legitimando sua ação perante a comunidade. Além disso, essa história pode ser compreendida como ferramenta de comunicação e como elemento de responsabilidade social e histórica.

Por fim, a partir desse trabalho, chamamos a atenção para uma nova investigação, que resgate da memória, que ouçam os sujeitos e arquivem documentos que possam auxiliar na construção de outros cursos voltados para a EJA no próprio campus e nos demais campus do IF Sudeste MG.

\section{Referências}

BARBOSA, Roscelino Quintão. Uma análise sobre a implantação do Proeja: Um estudo de caso no Ifet Sudeste de Minas Gerais - Campus Rio Pomba (2006 - 2008). 2010. Dissertação (Mestrado em Educação) - Faculdade de Educação, Universidade de Brasília, Brasília, 2010. Disponível em: https://repositorio.unb.br/handle/10482/9119. Acesso em: 10 out. 2019.

BRASIL. Ministério da Educação. Decreto $\mathbf{n}^{\mathbf{0}}$ 2.208, de 17 de abril de 1997. Regulamenta o $\S 2^{\circ}$ do art. 36 e os arts. 39 a 42 da Lei $n^{\circ} 9.394$, de 20 de dezembro 
Programa de Pós-graduação em Educação, Universidade Federal do Ceará

Fortaleza-CE-Brasil

de 1996, que estabelece as diretrizes e bases da educação nacional. Brasília, DF: Presidência da República, [2019]. Disponível em: http://www.planalto.gov.br/ccivil_03/decreto/D2208.htm. Acesso em: 05 nov. 2019.

. Ministério da Educação. Parecer $n^{\circ}$ 11/2000. Brasília, DF: Ministério da Educação: $\quad 92000 . \quad$ junho. Disponível em: http://www.forumeja.org.br/files/legisla\%C3\%A7\%C3\%A30\%202_0.pdf. Acesso em: 21 abril. 2020.

Ministério da Educação. Decreto $n^{\circ}$ 5.154, de 23 de julho de 2004. Regulamenta o $\S 2^{\circ}$ do art. 36 e os arts. 39 a 41 da Lei no 9.394 , de 20 de dezembro de 1996, que estabelece as diretrizes e bases da educação nacional, e dá outras providências. Brasília, DF: Presidência da República, [2019]. Disponível em: http://www.planalto.gov.br/ccivil_03/_ato2004-2006/2004/decreto/d5154.htm. Acesso em: 02 nov. 2019.

Ministério da Educação. Portaria $n^{\circ}$ 2.080/05. Brasília, DF: Ministério da Educação, 13 jun. 2005a. Disponível em: http://portal.mec.gov.br/setec/arquivos/pdf1/proejaportaria2080.pdf. Acesso em: 05 nov. 2019.

. Ministério da Educação. Decreto $n^{\circ}$ 5.478, de 24 de junho de 2005. Institui, no âmbito das instituições federais de educação tecnológica, o Programa de Integração da Educação Profissional ao Ensino Médio na Modalidade de Educação de Jovens e Adultos - PROEJA. Brasília, DF: Presidência da República, [2005b]. Disponível em: http://www.planalto.gov.br/ccivil_03/_Ato20042006/2005/Decreto/D5478.htm.Acesso em: 30 out. 2019.

Ministério da Educação. Decreto $\mathbf{n}^{\circ} \mathbf{5 . 8 4 0}$, de 13 de julho de 2006. Institui, no âmbito federal, o Programa Nacional de Integração da Educação Profissional com a Educação Básica na Modalidade de Educação de Jovens e Adultos - PROEJA. Brasília, DF: Presidência da República, [2019]. Disponível em: http://www.planalto.gov.br/ccivil_03/_Ato2004-006/2006/Decreto/D5840.htm

Ministério da Educação. PROEJA: Programa Nacional de Integração da Educação Profissional com a Educação Básica na Modalidade da Educação de Jovens e Adultos. Formação Inicial e Continuada / Ensino Fundamental - Documento Base. Brasília: MEC/SETEC, 2007. Disponível em: http://portal.mec.gov.br/setec/arquivos/pdf2/proeja_medio.pdf. Acesso em: 05 nov. 2019.

Ministério da Educação. Lei $\mathbf{n}^{\mathbf{0}} \mathbf{1 1 . 8 9 2}$, de 29 de dezembro de 2008. Institui a rede federal de educação profissional, científica e tecnológica, cria os institutos federais de educação, ciência e tecnologia, e dá outras providências. Brasília, DF: 
Revista Labor

Programa de Pós-graduação em Educação, Universidade Federal do Ceará

Fortaleza-CE-Brasil

Presidência da República, [2008]. Disponível em: http://www.planalto.gov.br/ccivil_03/_Ato2007-2010/2008/Lei/L11892.htm. Acesso em: 20 out. 2019.

- Ministério da Educação. Catálogo Nacional de Cursos Técnicos.

Brasília: MEC/SETEC, 2017. Disponível em: http://portal.mec.gov.br/docman/novembro-2017-pdf/77451-cnct-3a-edicao-pdf-1/file. Acesso em: 30 mar. 2020.

Ministério da Educação. Decreto n 9.465, de 02 de janeiro de 2019. Aprova a Estrutura Regimental e o Quadro Demonstrativo dos Cargos em Comissão e das Funções de Confiança do Ministério da Educação, remaneja cargos em comissão e funções de confiança e transforma cargos em comissão do Grupo-Direção e Assessoramento Superiores - DAS e Funções Comissionadas do Poder Executivo FCPE.. Brasília, DF: Presidência da República, [2019]. Disponível em: http://www.planalto.gov.br/ccivil_03/_Ato2015-2018/2018/Decreto/D9465.htm.Acesso em: 02 marc. 2020.

Centro Federal de Educação Tecnológica de Rio Pomba/MG. Projeto Pedagógico de Curso: Curso Técnico Integrado em Agente Comunitário de Saúde - PROEJACEFET-RP; Rio Pomba: 2008.

CIAVATTA, Maria. A formação integrada: a escola e o trabalho como lugares de memória e de identidade. Trabalho Necessário. ano 3, n. 3, p. 1-20, 2005. Disponível em: http://periodicos.uff.br/trabalhonecessario/article/viewFile/6122/5087. Acesso em: 11 out. 2019.

FRIGOTTO, Gaudêncio (Org). Institutos Federais de Educação, Ciência e Tecnologia: relação com o ensino médio integrado e o projeto societário de desenvolvimento. Rio de Janeiro: LPP, 2018. 320 p.

GIL, Antônio Carlos. Métodos e Técnicas de Pesquisa Social. 5. ed. São Paulo: Atlas, 2008. 200 p.

INSTITUTO FEDERAL DE EDUCAÇÃO, CIÊNCIA E TECNOLOGIA DO SUDESTE DE MINAS GERAIS. Plano de Desenvolvimento Institucional. Juiz de Fora, MG, 2014. Disponível em: https://www.ifsudestemg.edu.br/documentosinstitucionais/pdi/pdi-plano-de-desenvolvimento-institucional.pdf. Acesso em 04 abr. 2020.

INSTITUTO FEDERAL DE EDUCAÇÃO, CIÊNCIA E TECNOLOGIA DO SUDESTE DE MINAS GERAIS-CAMPUS RIO POMBA. Projeto Pedagógico de Curso: Curso Técnico Integrado em Agente Comunitário de Saúde - PROEJA- Campus Rio Pomba Rio Pomba: 2009. 
. Projeto Pedagógico de Curso: Curso Técnico Integrado em Agente Comunitário de Saúde - PROEJA- Campus Rio Pomba Rio Pomba: 2012.

JÚNIOR, Adenilson Souza Cunha. Saberes Construídos pelos professores nas práticas docentes na educação de pessoas jovens e adultas. Revista LABOR. Fortaleza, CE, v. 1, n.16, p. 66-79, 2016. Disponível em: http://www.periodicos.ufc.br/labor/article/view/6509/9946. Acesso em: 05 set. 2020.

MIRANDA, Paula Reis de. "O PROEJA vai fazer falta": uma análise de diferentes projetos educativos a partir dos discursos de estudantes nas aulas de Matemática. 2015. Tese (Doutorado em Educação). Faculdade de Educação, Universidade Federal de Minas Gerais, Belo Horizonte, 2015. Disponível em: https://repositorio.ufmg.br/handle/1843/BUBD-A7VPWU. Acesso em: 17 out. 2019.

MOURA, Dante Henrique. Educação básica e educação tecnológica: dualidade histórica e perspectivas de integração. Holos, ano 23, vol.2-2007. Disponível em: https://www2.ifrn.edu.br/ojs/index.php/HOLOS/article/viewFile/11/110. Acesso em: 17 out. 2019.

- Programa Nacional de Integração da Educação Profissional com a Educação Profissional com a Educação Básica na Modalidade de Educação de Jovens e Adultos - PROEJA: Entre potencialidades e entraves diante de projetos societários em disputa. Educação Profissional e Tecnológica em Revista, v. 1, n. 1, 2017. Disponível em: https://doi.org/10.36524/ept.v1i1.355. Acesso em: 20 maio. 2020.

RAMOS, Marise. Ensino médio integrado: Ciência, trabalho e cultura na relação entre educação profissional e educação básica. In: Jaqueline Moll e colaboradores. Educação Profissional e Tecnológica no Brasil Contemporâneo: Desafios, tensões e possibilidades. Porto Alegre, PR: Editora Artmed, 2010, v.1, p.43-57.

SILVA, Mônica Ribeiro da; ALMEIDA, Adriana de. A problemática da evasão no processo de implantação do PROEJA no Estado do Paraná. In: Mônica Ribeiro da Silva; Mário Lopes Amorim; Edaguimar Orquizas Viriato. (Org.). PROEJA: educação profissional integrada à EJA: entre políticas e práticas. Curitiba - Pr: Editora da UTFPR, 2011, v. 1, p. 133-159.

\section{Nara Soares Costa}

Rio Pomba, MG, Brasil.

Mestranda em Educação Profissional e Tecnológica pelo Instituto Federal do Sudeste de Minas GeraisCampus Rio Pomba. Atualmente é servidora pública no Instituto Federal de Educação, Ciência e Tecnologia do Sudeste de Minas Gerais- Campus Rio Pomba.

Email: nara.costa@ifsudestemg.edu.br

Link do Lattes: http: http://lattes.cnpq.br/6123397563459065 


\section{Revista Labor}

Programa de Pós-graduação em Educação, Universidade Federal do Ceará

Fortaleza-CE-Brasil

\section{Beatriz Gonçalves Brasileiro}

Muriaé, MG, Brasil.

Atualmente é professor do Instituto Federal do Sudeste de Minas Gerais. Docente do Curso Técnico Integrado em Agroecologia e do Curso de Mestrado em Educação Profissional e Tecnológica (ProfEPT). Tem experiência na área de Agronomia, com ênfase em Produção vegetal, atuando principalmente nos seguintes temas: sementes, plantas medicinais, agroecologia e educação profissional e tecnológica.

Email: beatriz.brasileiro@ifsudestemg.edu.br

Link do Lattes: http://lattes.cnpq.br/8060901148976333

\section{Paula Reis de Miranda}

Rio Pomba, MG, Brasil.

Atualmente é professora do IF Sudeste de Minas Gerais - Campus Rio Pomba e coordenadora da Especialização em Ensino de Matemática e Física. Atua como professora do ProfEPT. Tem experiência na área de Educação Matemática, com ênfase em Fundamentos da Matemática e Educação de Jovens e Adultos.

Email: paula.reis@ifsudestemg.edu.br

Link do Lattes: http: http://lattes.cnpq.br/3080296488422831

Recebimento: $26 / 07 / 2020$

Aprovação: 16/09/2020

\section{Q.Code}

\section{Editores-Responsáveis}

Dr. Enéas de Araújo Arrais Neto, Universidade Federal do Ceará, UFC, Ceará, Brasil

Dr. Sebastien Pesce, Universidade de Orléans, França 